Tropical Journal of Pharmaceutical Research February 2016; 15 (2): 275-283

ISSN: $1596-5996$ (print); 1596-9827 (electronic)

(C) Pharmacotherapy Group, Faculty of Pharmacy, University of Benin, Benin City, 300001 Nigeria.

All rights reserved.

Available online at http://www.tjpr.org

Original Research Article

http://dx.doi.org/10.4314/tjpr.v15i2.8

\title{
Proliferative Activity and Neuroprotective Effect of Ligustrazene Derivative by Irritation of Vascular Endothelial Growth Factor Expression in Middle Cerebral Artery Occlusion Rats
}

\author{
Zhang Huazheng ${ }^{1}$, Wang Penglong ${ }^{2}$, Ren Liwei ${ }^{1}$, Wang Xiaobo ${ }^{2}$, Li Guoliang ${ }^{2}$, \\ Wang Mina', Chu Fuhao ${ }^{2}$, Gong Yan ${ }^{2}, \mathrm{Xu} \mathrm{Bing}^{2}$, Bi Siling1, Lei Haimin ${ }^{2}$ and \\ Zhang Yuzhong ${ }^{1 \star}$ \\ ${ }^{1}$ Department of Pathology, ${ }^{2}$ School of Chinese Pharmacy, Beijing University of Chinese Medicine, Beijing, 100102, China
}

*For correspondence: Email: hm_lei@126.com, zyz100102@126.com; Tel: +86-10-6428-6964, +86-10-8473-8640

Received: 4 August 2015

Revised accepted: 29 December 2015

\begin{abstract}
Purpose: To investigate the proliferative activity and neuroprotective effect of a newly identified ligustrazine derivative (4-((3,5,6-trimethylpyrazine-2-yl)methoxyl)-3-methox-ybenzoic acid-3,5,6trimethylpyrazin-2-methyl ester, T-VA) and the possible mechanism related to vascular endothelial growth factor (VEGF) in cerebral ischemic injury.

Methods: The pharmacological activity of T-VA was evaluated using MTT ((3-(4,5-dimethylthiazolyl2yl)-2,5-diphenyltetrazolium bromide)) assay, while cellular morphology was observed with hematoxylin and eosin (HE) staining. Chick chorioallantoic membrane (CAM) model, immuno-histochemical analysis, and enzyme-linked immunosorbent assay (ELISA) were used to determine the expression of VEGF. Middle cerebral artery occlusion (MCAO) model was used to investigate both VEGF expression and the survival rate after treatment with T-VA.

Results: T-VA promoted neuron activity, and the doses of 15 and $30 \mu \mathrm{M}$ showed more significant effect $(p<0.05)$. The viability of PC12 cells increased significantly in T-VA $(30$ and $60 \mu M)$ groups $(p<0.05)$ and increased in a dose-dependent manner. Immunohistochemical analysis showed stimulated VEGF expression, and CAM model results showed that T-VA $(20 \mathrm{mg} / \mathrm{egg})$ significantly promoted microangiogenesis $(p<0.01)$. Moreover, in MCAO model, the survival rate of T-VA $(60 \mathrm{mg} / \mathrm{kg})$ group reached $86.7 \%$ while for the ischemia group it was $60.0 \%$. In addition, ELISA results showed that T-VA promoted the expression of VEGF $(p<0.05)$.

Conclusion: These findings indicate that T-VA helps to prevent ischemic injury by increasing VEGF expression.
\end{abstract}

Keywords: Ligustrazine, Neuron, PC12 cell, Chick Chorioallantoic Membrane, Middle Cerebral Artery Occlusion, Vascular Endothelial Growth Factor

Tropical Journal of Pharmaceutical Research is indexed by Science Citation Index (SciSearch), Scopus, International Pharmaceutical Abstract, Chemical Abstracts, Embase, Index Copernicus, EBSCO, African Index Medicus, JournalSeek, Journal Citation Reports/Science Edition, Directory of Open Access Journals (DOAJ), African Journal Online, Bioline International, Open-J-Gate and Pharmacy Abstracts

\section{INTRODUCTION}

Ischemic stroke has attracted attention in domestic and international research, and several reviews have recently been published about the effect and potential benefits of traditional Chinese medicine in the treatment of cerebral ischemic injury [1]. It has been suggested that some herbal medicines, or their products, may have the functions of improving microcirculation 
in the brain, protecting against ischemic injury, improving cerebrovascular properties, and inhibiting neuron apoptosis [2-4]. The lack of effective and widely applicable pharmacological treatments for ischemic stroke patients may explain the growing interest in discovering drugs derived from traditional medicines [5].

As one of the major effective ingredients of Rhizoma Chuanxiong ligustrazine (2,3,5,6tetramethylpyrazine, TMP) has been widely used in the treatment of ischemic stroke and cerebrovascular disease in China for many years [6] Previous studies have shown various pharmacological activities of TMP, such as antimyocardial ischemia, anti-cerebral ischemia, inhibiting platelet aggregation, protecting vascular endothelial, etc [7-11]. To further improve the neuroprotective property of TMP, we decided to undertake a study of a novel series of TMP derivatives based on the principles of hybridization and prodrug design in medicinal chemistry and acquired compounds with pharmacologically additive or synergetic e $\square$ ects [12-14]. It has been demonstrated that T-VA ((4((3,5,6-trimethylpyrazine-2-yl)methoxyl)-3-

methoxybenzoic acid-3,5,6-trimethylpyrazin- 2methyl ester; see Results, Figure 1A) has a promising protective effect against $\mathrm{CoCl}_{2-}$ induced neurotoxicity in differentiated PC12 cells $\left(\mathrm{EC}_{50}=4.249 \mu \mathrm{M}\right)[15]$ and that the plasma concentration of T-VA reaches peak levels between 4 and $6 \mathrm{~h}$ post-intragastric administration [16]. Interestingly, some studies show that congener structures of T-VA possess protective effects on damaged vascular endothelial cells, such as ECV-304 cells, human umbilical vein endothelial cells (HUVECs) and Hy-926 cells [17-19]. Moreover, ligustrazine derivatives showed good antiplatelet aggregation activity [19].

Based on the aforementioned evidence, we reasoned that the neuroprotective effect of T-VA might be associated with its thrombolytic and vascular biological properties. Vascular endothelial growth factor (VEGF), an angiogenic protein, is able to enhance survival ability of endothelial cells and has a role in thrombus resolution that was helpful in the treatment of cerebral ischemia $[20,21]$. This potential therapeutic value and neuroprotective effect in ischemia might be mediated by VEGF itself or by a signal transduction pathway activated by VEGF [22]. VEGF was shown to attenuate acute neuronal death and play a neuroprotective role under oxygen-glucose deprivation conditions through VEGFR-2 [23]. Moreover, when VEGF was used to treat focal cerebral ischemia in rats, the infarct volume was reduced and neurological functions were improved [24]. Therefore, our aim was to investigate the proliferative activity and neuroprotective effect of T-VA and the possible mechanism related to VEGF in cerebral ischemic injury.

\section{EXPERIMENTAL}

\section{General}

Rats (female rats pregnant for $16-18$ days and male SD rats weighing 280-300 g) were purchased from Beijing Vital River Laboratory Animal Technology Company Limited (Beijing, China) and kept under standard laboratory conditions (tap water, constant room temperature, $22{ }^{\circ} \mathrm{C}$ ). All animal protocols were approved by the Ethics Committee of Beijing University of Chinese Medicine in accordance with the National Institutes of Health guidelines (Contract 2012-0036, June 2012). All efforts were made to minimize animal suffering and to reduce the number of animals used. PC12 cell line was purchased from the Institute of Materia Medica of the Chinese Academy of Medical Science. Fertilized White Leghorn chicken eggs were provided by Chinese Academy of Agricultural Sciences.

\section{Animals, neurons culture and drugs}

Fetal rats were taken from pregnant rats and washed twice with $4{ }^{\circ} \mathrm{C}$ phosphate buffered saline (PBS). After stripping the meninges and vessels, the brains of fetal rats were cut into 1 $\mathrm{mm}^{3}$ cubes. All steps were conducted on ice. Neurons were isolated by $0.1 \%$ trypsin digestion for $10 \mathrm{~min}$ in a $37^{\circ} \mathrm{C}$ incubator and fixed with Dulbecco's modified eagle medium supplemented with $10 \%(\mathrm{v} / \mathrm{v})$ fetal bovine serum and $100 \mathrm{U} / \mathrm{mL}$ penicillin-streptomycin (Thermo Technologies, New York, NY, USA) [25,26]. Then neurons were seeded onto poly-L-lysinecoated 96-well culture plates at $8 \times 10^{4}$ cells $/$ well, and the plates were incubated at $37{ }^{\circ} \mathrm{C}$ in a humidified atmosphere of $5 \% \mathrm{CO}_{2}$ for $48 \mathrm{~h}$. Subsequently, the neurons were treated with different doses of T-VA $(60,30$, and $15 \mu \mathrm{M})$ and nimodipine (NMDP) for $24 \mathrm{~h}$.

\section{PC12 cell culture and drugs}

PC12 cells were cultured in RPMI 1640 medium supplemented with $5 \%(\mathrm{v} / \mathrm{v})$ fetal bovine serum, $10 \%(\mathrm{v} / \mathrm{v})$ horse serum and $100 \mathrm{U} / \mathrm{mL}$ penicillinstreptomycin (Thermo Technologies, New York, NY, USA) at $37^{\circ} \mathrm{C}$ in a humidified atmosphere of $5 \% \mathrm{CO}_{2}$. When cells achieved the desired 
density of $>80 \%$ confluency, the original medium was removed and cells were cultured with a serum-free medium for 12-14 $\mathrm{h}$. Then the cells were suspended in the RPMI 1640 medium supplemented with $10 \%(\mathrm{v} / \mathrm{v})$ fetal bovine serum, and seeded into poly-L-lysine-coated 96-well culture plates at $7 \times 10^{4}$ cells/well, differentiated by treated with nerve growth factor (NGF; 50 $\mathrm{ng} / \mathrm{mL})$ for $48 \mathrm{~h}$ [2]. Subsequently, the differentiated PC12 cells were treated for $36 \mathrm{~h}$ with various concentrations $(60,30,15 \mu \mathrm{M})$ of $\mathrm{T}$ VA or RPMI 1640 medium supplemented with 10 $\%$ (v/v) fetal bovine serum. T-VA was dissolved in dimethyl sulfoxide (DMSO). The final concentration of DMSO was $<0.1 \%(\mathrm{v} / \mathrm{v})$.

\section{MTT (3-(4,5-dimethylthiazolyl2-yl)-2,5- diphenyltetrazolium bromide) assay}

After MTT solution ( $20 \mu \mathrm{L}, 5 \mathrm{mg} / \mathrm{mL}$ ) was added to each well, the plate was incubated for an additional $4 \mathrm{~h}$ at $37^{\circ} \mathrm{C}$. The supernatant was removed carefully by pipetting from wells without disturbing the attached cells. Formazan crystals were solubilized by adding $150 \mu \mathrm{L}$ of DMSO to each well, and then the plate was shaken for 15 $\min$ [2]. The absorbance of neurons at $540 \mathrm{~nm}$ and PC12 cells at $490 \mathrm{~nm}$ were measured with a Bio-Rad 550 spectrophotometer (Bio-rad, California, CA, USA).

\section{Hematoxylin and eosin (HE) staining method}

After pretreatment with the serum-free medium for 12-14 h, cells were seeded at a concentration of $7 \times 10^{4} \mathrm{cell} / \mathrm{mL}$ on a poly-L-lysine-coated sterile cover slip in 24-well tissue culture plates, and differentiated by treatment with NGF (50 $\mathrm{ng} / \mathrm{mL}$ ) for $48 \mathrm{~h}$. The differentiated PC12 cells were pretreated with T-VA for $36 \mathrm{~h}$ at the optimum concentration $(60 \mu \mathrm{M})$, which was selected by MTT assay. Cover slips were washed twice with PBS, removed and treated with acetone for $10 \mathrm{~min}$ at $-20{ }^{\circ} \mathrm{C}$. Then cells were washed with PBS and stained with hematoxylin for $3 \mathrm{~min}$. The stained nuclei were rinsed with running water for $1 \mathrm{~h}$ followed by eosin staining for another 2 min. Finally, stained sections were dehydrated using gradient ethanol and cleared in xylene [2,27]. The cellular morphology was photographed by light microscopy (Nikon, Kobe, Japan).

\section{Immunohistochemical analysis of VEGF}

Our previous study demonstrated that T-VA protect $\mathrm{CoCl}_{2}$-induced neurotoxicity in differentiated PC12 cells [2], so all measurements were performed after PC12 cells were induced by $\mathrm{CoCl}_{2}$ (dissolved in RPMI 1640 medium, $200 \mathrm{mM}$ ) for $12 \mathrm{~h}$. Cells in the NGF group were not treated with T-VA and $\mathrm{CoCl}_{2}$. Briefly, after being washed three times with PBS, $\mathrm{PC} 12$ cells were fixed in acetone for $10 \mathrm{~min}$ at $20{ }^{\circ} \mathrm{C}$. After being blocked in $3 \% \mathrm{H}_{2} \mathrm{O}_{2}-\mathrm{CH}_{3} \mathrm{OH}$ for $30 \mathrm{~min}$ at $37^{\circ} \mathrm{C}$, the cells were incubated with VEGF antibodies overnight at $4{ }^{\circ} \mathrm{C}$. Cells were then incubated in horseradish peroxidaseconjugated AffiniPure goat anti-rabbit immunoglobulin G (lgG) diluted to 1:250 in PBS for $30 \mathrm{~min}$ at $37^{\circ} \mathrm{C}$, followed by streptavidinbiotin complex (SABC) for $30 \mathrm{~min}$ at $37^{\circ} \mathrm{C}$. 3, 3Diaminobenzidine (DAB) was used as a chromogen for $10 \mathrm{~min}$. PBS was used between each step to wash the cover slips. Finally, PC12 cells were stained with hematoxylin for 30-60 s and washed with running water for $1 \mathrm{~h}$. Stained sections were dehydrated using gradient ethanol and cleared in xylene. The expression of VEGF was observed and photographed under a microscope [28].

\section{Chick chorioallantoic membrane (CAM) model}

The eggs were placed in an incubator immediately after embryogenesis started and were kept under constant humidity of $65 \%$ at 37 ${ }^{\circ} \mathrm{C}$. On the 7th day, a square window was opened on the shell and physiological saline $(0.1$ $\mathrm{mL}$ ) was injected in to detach the shell membrane. T-VA was carried by gelatin sponges and implanted at 10 and $20 \mu \mathrm{g} / \mathrm{egg}$. The control group was treated with physiological saline. The windows were sealed with medical adhesive tape. The aforementioned treatment steps were all performed under sterile conditions. On the 11 th day, the tape was removed and the entire CAM was detached after tissue fixation with methanol/acetone $(1: 1, \mathrm{v} / \mathrm{v})$. Then, computerassisted image tracking was used to obtain absolute values for the number of microvessels that were 1-100 $\mu \mathrm{m}$ in diameter [15]. The model was established according to previously published method [29] and our previous studies [30].

\section{Middle cerebral artery occlusion (MCAO) model}

Transient MCAO was conducted in male rats according to the previously published methods [31,32]. There were 15 rats in each of the MCAO and sham-operated groups. Briefly, male rats were anesthetized with $10 \%$ chloral hydrate (350 $\mathrm{mg} / \mathrm{kg}$ ), and the right common carotid artery and external carotid arteries were isolated and ligated. A nylon suture (diameter $0.25 \mathrm{~mm}$ ) was advanced from the common carotid artery to the internal carotid artery for a distance of 
approximately $18-20 \mathrm{~mm}$ from the externalinternal carotid artery. The blocking of the middle cerebral artery induced cerebral ischemia. Then the muscle and skin were sutured with 4-0 nylon. Penicillin (4 million units $/ \mathrm{mL}$ ) was given to the rats for 3 days following the operation. In shamoperated rats, internal and external carotid arteries were also exposed and separated. When the rats recovered consciousness, $6 \mathrm{~h}$ after the operation, scores were graded as follows: according to Bederson's description [33]: 0, no deficit; 1, failure to fully extend left forepaw; 2, circling to the left; 3 , falling to the left; 4, no spontaneous walking with a depressed level of consciousness. Rats with scores from 1 to 3 were selected for further testing and were divided randomly to the ischemia group, T-VA group (120 $\mathrm{mg} / \mathrm{kg}$ and $60 \mathrm{mg} / \mathrm{kg}$ ), and NMDP group. The rats were treated with T-VA by intragastric administration $(1 \mathrm{~mL} / 100 \mathrm{~g})$ once a day until the 10 th day. The sham and model groups were treated with isovolumetric $0.5 \%$ sodium carboxymethyl cellulose (CMC-Na).

\section{Enzyme-linked immunosorbent assay (ELISA) for VEGF detection}

The level of VEGF in serum was measured with sandwich ELISA kits. Optical densities were determined at $450 \mathrm{~nm}$ with a Bio-Rad 550 spectrophotometer.

\section{Statistical analysis}

Statistical comparisons between groups were made by one-way ANOVA followed by Student's t-test using the SPSS version 20. Results were considered significant at $p<0.05$.

\section{RESULTS}

\section{Effect of T-VA on neuron activity}

As shown in Figure 1B, the control group was set as $100 \%$ neuronal activity based on the optical density (OD) values of the MTT assay. T-VA promoted neuron activity in all treatment groups, but the doses of 15 and $30 \mu \mathrm{M}$ showed more significant effect $(p<0.05)$ than the high dose of $60 \mu \mathrm{M}$. The activity of neurons in NMDP group also increased compared with the control group. Under optical microscopy, neurons in control group exhibited pyramidal cell body with fine dendritic networks (Figure 1C). More neurons are evident in the NMDP group compared with control group (Figure 1D). In addition, the number of neurons and the dendritic networks increased with various concentrations of T-VA. Notably, the T-VA doses of 15 and $30 \mu \mathrm{M}$ induced better neuron growth than the high dose $(60 \mu \mathrm{M})$ group (Figures 1E-1G).

\section{Effect of T-VA on differentiated PC12 cells}

The NGF group was set as $100 \%$ activity of PC12 cells. Results of the MTT assay showed that T-VA at 15, 30, and $60 \mu \mathrm{M}$ increased cell viability to $110.14 \%, 128.99 \%$ and $144.93 \%$, respectively in a dose-dependent manner. Observation of morphologic changes of PC12 cells revealed that undifferentiated PC12 cells proliferated to form clone-like cell clusters without neural characteristics (Figure 2B), that PC12 cells differentiated by NGF had round cell bodies with fine dendritic networks and intact and clear cell edges (Figure 2C), and that cells in NMDP group had long synapse (Figure 2D). PC12 cells treated with T-VA had the longest synapse of all the groups and an obvious increase in the amount of neurite-bearing cells compared with the control group (Figure 2E).

\section{Expression of VEGF in differentiated PC12 cells}

The immunohistochemical results of VEGF are represented in Figure 3. The $\mathrm{CoCl}_{2}$ group showed weak expression of VEGF (Figure 3B). The brown staining of the NGF and NMDP groups was obviously increased (Figures $3 \mathrm{~A}$ and $3 \mathrm{C})$. Moreover, the T-VA group $(60 \mu \mathrm{M})$ displayed significant expression of VEGF compared with the $\mathrm{CoCl}_{2}$ group (Figure 3D).

\section{Microvascular proliferation of T-VA on CAM}

T-VA had microvascular proliferation effect on CAM. When the dose of T-VA was $10 \mu \mathrm{g} / \mathrm{egg}$, the impact of promoting microvascular proliferation was not very obvious (Figures 4A and $4 \mathrm{C}$ ). However, when the dose was increased to $20 \mu \mathrm{g} / \mathrm{egg}$, microvascular proliferation increased significantly compared with control group $(p<0.01)$ (Figure 4A). As exhibited in Figure 4D, we found that the amount of microvascular distinctly increased compared with the control group.

\section{Effect of T-VA on survival rate and VEGF expression in rats with MCAO}

Both survival rate and VEGF expression were markedly reduced in MCAO rats with ischemia compared with survival rate and VEGF expression in sham-operated rats, which were set as $100 \%$ (Figures $5 \mathrm{~A}$ and $5 \mathrm{~B}$ ). Survival rates in MCAO rats after treatment with 120 and 60 
$\mathrm{mg} / \mathrm{kg}$ of T-VA were increased by 6.7 and 26.7 $\%$, respectively, compared with the survival rate in the untreated MCAO ischemia group. The survival rate in the MCAO rats after treatment with NMDP was also increased (by $20 \%$ ) compared with the survival rate in the untreated MCAO ischemia group. The areas of VEGF expression, determined by both ELISA and immunohistochemistry (IHC), were significantly decreased in the untreated MCAO ischemia group compared with VEGF expression in the sham-operated group (Figure 5B).

The results of immunohistochemistry (IHC) are in agreement with the ELISA results. ELISA results revealed that the VEGF expression increased significantly in the T-VA $(60 \mathrm{mg} / \mathrm{kg}$ ) group (Figure $5 B$ ) and IHC results revealed a significant increase in VEGF expression in both T-VA treatment groups (60 and $120 \mathrm{mg} / \mathrm{kg}$ ) compared with that in the untreated MCAO ischemic group. The contents of VEGF in the 60 and $120 \mathrm{mg} / \mathrm{kg}$ T-VA treatment groups were 25.67 and 22.86 $\mathrm{ng} / \mathrm{mg}$ protein, respectively, which corresponds to a $26.26 \%$ and $16.28 \%$ increase, respectively, compared with the VEGF content in the untreated MCAO ischemia group (18.28 $\mathrm{ng} / \mathrm{mg}$ protein). NMDP treatment did not significantly improve the VEGF expression in rats with MCAO.<smiles>COc1cc(C(=O)OCc2nc(C)c(C)nc2C)ccc1OCc1nc(C)c(C)nc1C</smiles>

A: Structure of T-VA

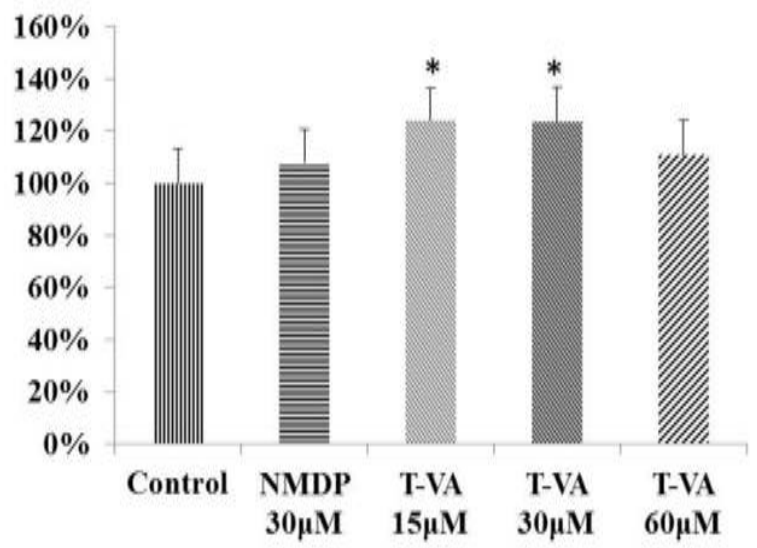

B: Activity of neurons.
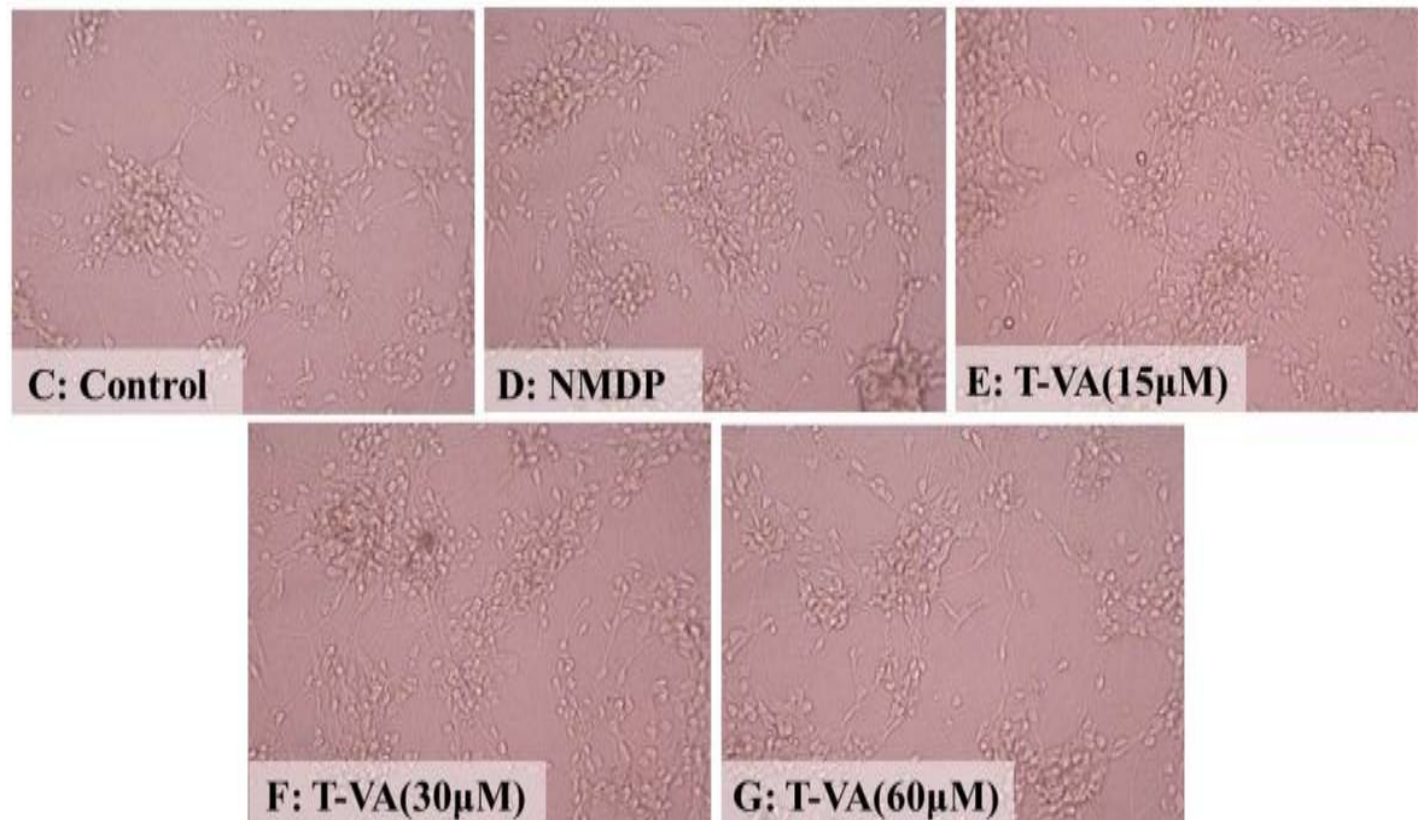

F: T-VA(30 $\mu M)$

G: T-VA $(60 \mu M)$

Figure 1: (A) Structure of T-VA. (B) Activity of neurons treated with T-VA. * $p<0.05$, compared with control group. (C) The morphology of neurons in control group. (D) The morphology of neurons treated with NMDP. (EG) The morphology of neurons treated with T-VA $(15,30$, and $60 \mu \mathrm{M}) .(\times 20)$ 

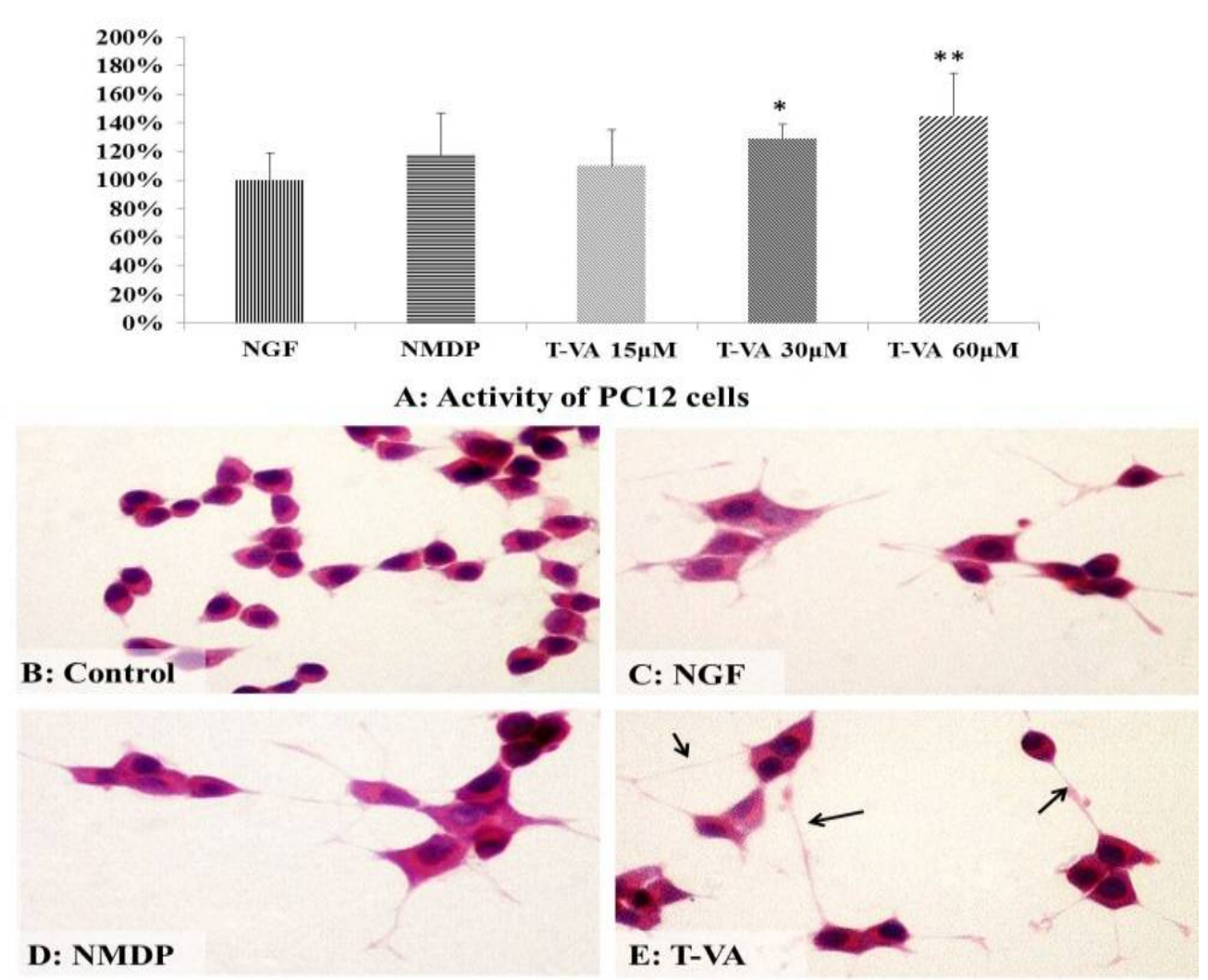

Figure 2: Effect of T-VA on PC12 cells. (A) Activity of differentiated PC12 cells. * $p<0.05$, compared with control group. ${ }^{* *} p<0.01$, compared with control group. (B) Undifferentiated PC12 cells (C) PC12 cells differentiated by NGF. (D) Differentiated PC12 cells treated with NMDP. (E) Differentiated PC12 cells treated with T-VA (60 $\mu M)$. $(\times 400)$
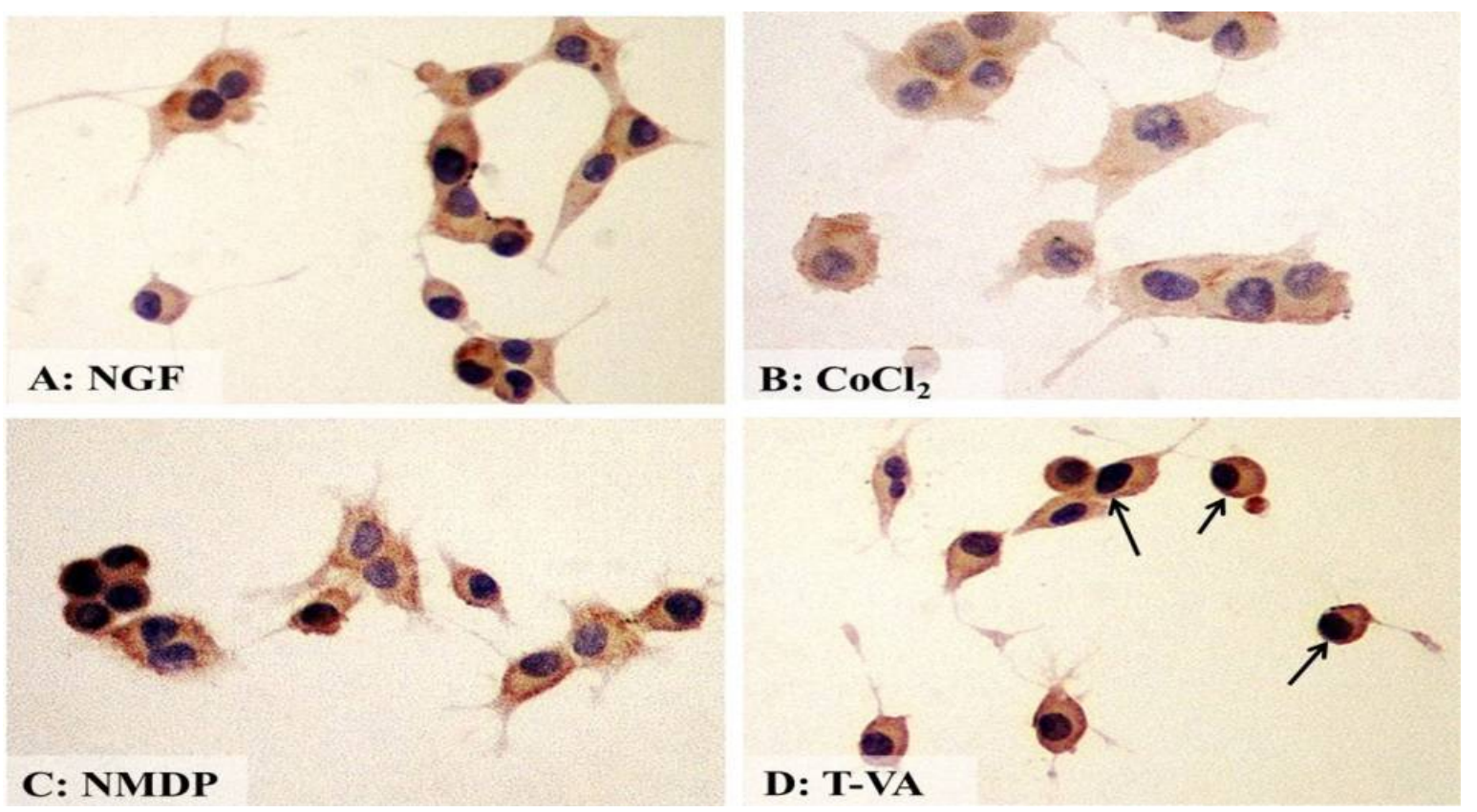

Figure 3: Expression of VEGF in differentiated PC12 cells. (A) PC12 cells differentiated by NGF. (B) Differentiated PC12 cells exposed to $\mathrm{CoCl}_{2}$ insult. (C) Differentiated PC12 cells pre-incubated with NMDP and then exposed to $\mathrm{CoCl}_{2}$ insult. (D) Differentiated PC12 cells pre-incubated with T-VA $(60 \mu \mathrm{M})$ and then exposed to $\mathrm{CoCl}_{2}$ insult. $(\times 400)$ 


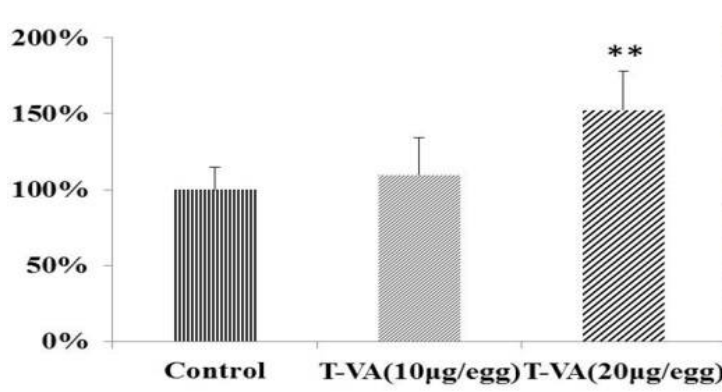

A: The number of microvessels

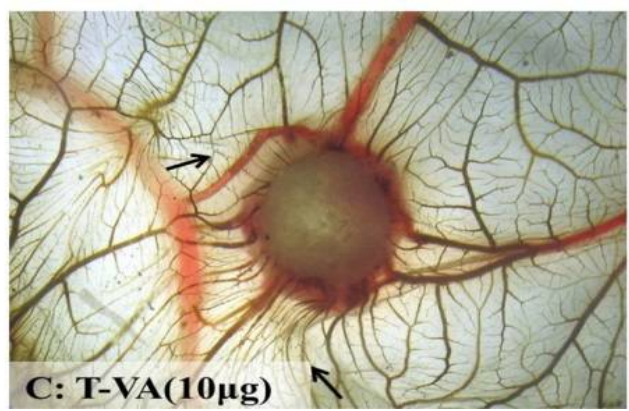

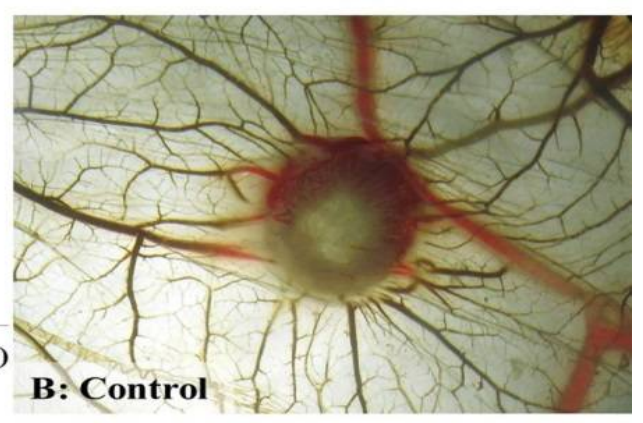

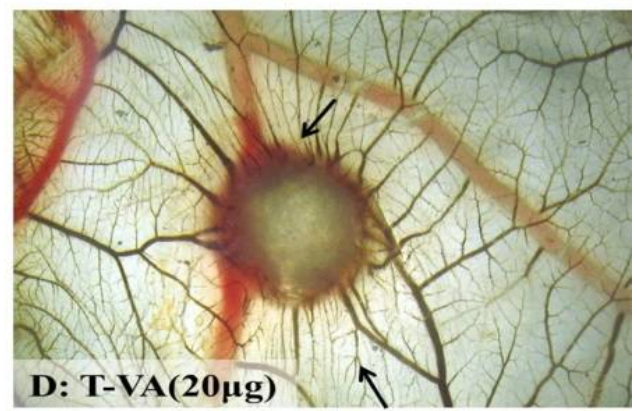

Figure 4: Microvascular proliferation of T-VA on CAM $(n=7)$. (A) The number of microvasessels on CAM model. ** $p<0.01$, compared with control group. (B) Control. (C) $10 \mu \mathrm{g} / \mathrm{egg}$ for T-VA group. (D) $20 \mu \mathrm{g} / \mathrm{egg}$ for T-VA group $(\times 50)$

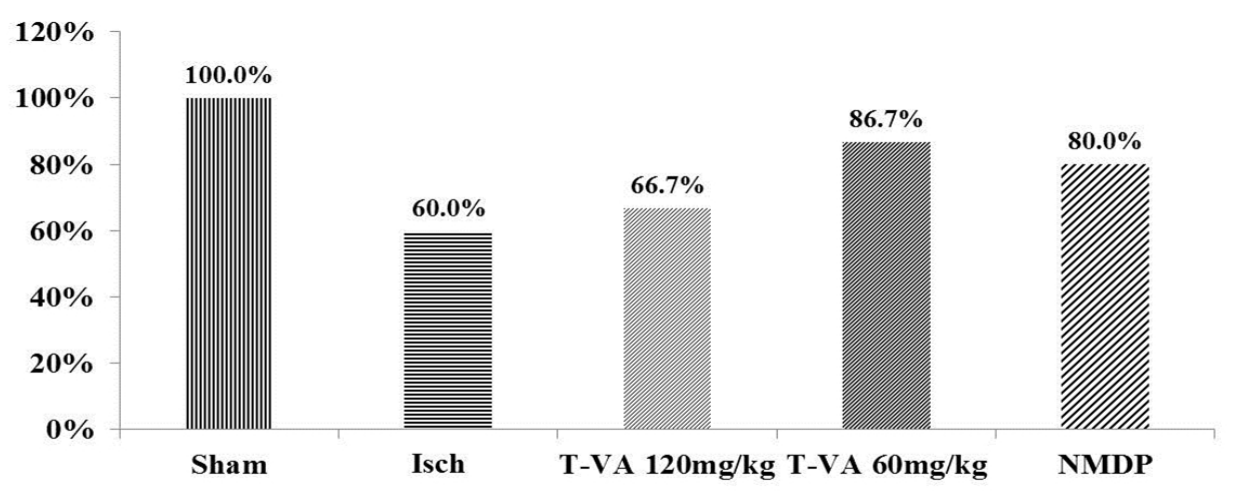

A: Survival rate of rats with MCAO $(n=15)$.

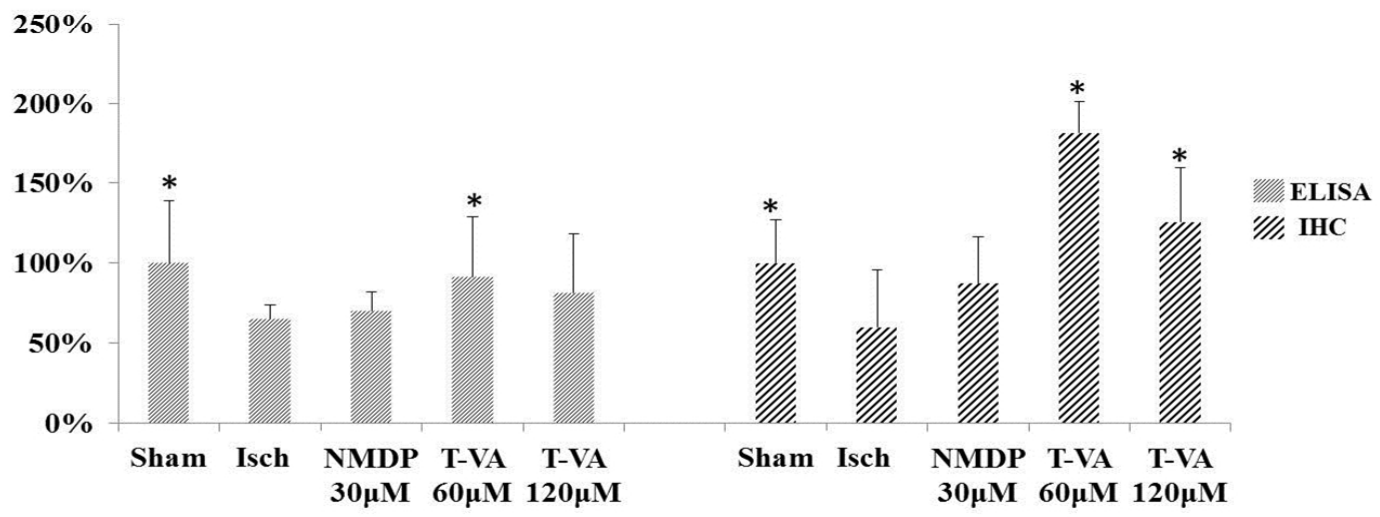

B: VEGF expression in rats with MCAO by ELISA and IHC

Figure 5: (A) Survival rate of rats with MCAO. (Survival rate = survival rats after 10 days of treatment/original 15 rats of each group); (B) Effect of T-VA on VEGF in rats with MCAO. * $p<0.05$, compared with untreated MCAO ischemia group. Results are shown for ELISA (left, gray bars) and IHC (right, hashed bars) 


\section{DISCUSSION}

It was previously reported that T-VA has a protective effect against injured PC12 cells $\left(E_{50}\right.$ $=4.249 \mu \mathrm{M}$ ), whereas the congener structures of T-VA possess protective effects against damaged vascular endothelial cells [17-19]. In the present study, T-VA displayed the ability to promote the activities of neurons and PC12 cells $(p<0.05)$, and histopathological analyses coincided with the cell viability detected by the MTT assay. Overall, T-VA exhibited a positive effect on neurons in this study.

VEGF, a major mediator of angiogenesis, plays an important role in recovery of ischemic injury and serves as a useful positive control $[34,35]$. Our present study showed that T-VA exhibited the ability to stimulate VEGF expression in PC12 cells. Further study using CAM model showed that T-VA significantly promoted microangiogenesis $(p<0.01)$. These findings suggest that there might be a correlation between VEGF expression and cell viability. When the rats were treated with T-VA, VEGF up-regulated dramatically, thereby preventing MCAO rats from ischemic injury. Additionally, this study indicates that the survival rate of MCAO rats after treatment with T-VA was $26.67 \%$ higher than that in the ischemia group, suggesting an effective approach against ischemic injury.

Obviously, it is of vital importance to increase the survival rate for the patients. All the findings in present study suggest that the neuroprotective effect of T-VA may be related to an increase of VEGF expression, laying the foundation for further research of the mechanism. This study also indicates the feasibility of discovering more efficient compounds from traditional Chinese medicine via structure combination.

\section{CONCLUSION}

T-VA promotes the activities of neurons and differentiated $\mathrm{PC} 12$ cells and increases the expression of VEGF both in vitro and in vivo in rats. Therefore, T-VA may be a potential candidate in preventing cerebral ischemic injury.

\section{ACKNOWLEDGEMENT}

The authors gratefully acknowledge support of this work by National Natural Science Foundation of China (no. 81173519) as well as Innovation Team Project Foundation of Beijing University of Chinese Medicine (Lead Compounds Discovering and Developing Innovation Team Project Foundation, no. 2011-CXTD-15), and
Young Teachers' Scientific Research Project of Beijing University of Chinese Medicine (no. 2015JYB-JSMS023).

\section{REFERENCES}

1. Feigin VL. Herbal Medicine in Stroke Does It Have a Future? Stroke 2007; 38:1734-1736.

2. Ren $Z L$, Zuo PP. Neural regeneration: role of traditional Chinese medicine in neurological diseases treatment. $J$ Pharmacol Sci 2012; 120: 139-145.

3. Cai G, Liu B, Liu W, Tan X, Rong J, Chen X, Tong L, Shen J. Buyang Huanwu Decoction can improve recovery of neurological function, reduce infarction volume, stimulate neural proliferation and modulate VEGF and Flk1 expressions in transient focal cerebral ischaemic rat brains. J Ethnopharmacol 2007; 113: 292299.

4. Zhou L, Zuo Z, Chow MS. Danshen: an overview of its chemistry, pharmacology, pharmacokinetics, and clinical use. J Clin Pharmacol 2005; 45: 1345-1359.

5. Wang $S, H u Y$, Tan $W, W u X$, Chen R, Cao J, Chen M, Wang $Y$. Compatibility art of traditional Chinese medicine: from the perspective of herb pairs. $J$ Ethnopharmacol 2012; 143: 412-423.

6. Xu D, Duan $H$, Zhang Z, Cui W, Wang L, Sun $Y$, Lang $M$, Hoi PM, Han $Y$, Wang $Y$, Lee SM. The novel tetramethylpyrazinebis-nitrone (TN-2) protects against MPTP/MPP+-induced neurotoxicity via inhibition of mitochondrial-dependent apoptosis. J Neuroimmune Pharmacol 2014; 9: 245-258.

7. Lv L, Jiang SS, Xu J, Gong JB, Cheng Y. Protective effect of ligustrazine against myocardial ischaemia reperfusion in rats: the role of endothelial nitric oxide synthase. Clin Exp Pharmacol Physiol 2012; 39: 20-27.

8. Zhang $C$, Teng F, Tu J, Zhang D. Ultrasound-enhanced protective effect of tetramethylpyrazine against cerebral ischemia/reperfusion injury. PLoS One 2014.

9. Kao TK, Chang CY, Ou YC, Chen WY, Kuan YH, Pan HC, Liao SL, Li GZ, Chen CJ. Tetramethylpyrazine reduces cellular inflammatory response following permanent focal cerebral ischemia in rats. Exp Neurol 2013; 247: 188-201.

10. Kang $Y$, Hu M, Zhu $Y$, Gao X, Wang MW. Antioxidative effect of the herbal remedy Qin Huo Yi Hao and its active component tetramethylpyrazine on high glucosetreated endothelial cells. Life Sci 2009; 84: 428-436.

11. Chen $Z Q$, Hong $L$, Wang $H$. Effect of tetramethylpyrazine on platelet activation and vascular endothelial function in patients with acute coronary syndrome undergoing percutaneous coronary intervention. Zhongguo Zhong Xi Yi Jie He Za Zhi. 2007; 27: 1078-1081.

12. Wang $P L$, Zhang HG, Chu FH, Xu X, Lin JX, Chen CX, Li $G L$, Cheng YT, Wang $L$, Li $Q$, et al. Synthesis and protective effect of new ligustrazine-benzoic acid derivatives against CoCl2-induced neurotoxicity in differentiated PC12 cells. Molecules 2013; 18: 1302713042.

Trop J Pharm Res, February 2016; 15(2): 282 
13. Li GL, Wang P, Xu X, Lin, J.; Chu F, Song J, Zhou S, Wang $M$, Zhang $Y$, Lei $H$. Synthesis and protective effect of ligustrazine intermediates against CoCl2induced neurotoxicity in differentiated PC12 Cell. Chin J Chin Mater Med 2014; 39: 2679-2683.

14. Li G, Xu X, Xu K, Chu F, Song J, Zhou S, Xu B, Gong Y, Zhang $H$, Zhang $Y$, et al. Ligustrazinyl amides, a novel class of ligustrazine-phenolic acid derivatives with neuroprotective effects. Chem Cent J 2015; 9: 1-9.

15. Wang $P$, She G, Yang $Y$, Li Q, Zhang $H$, Liu J, Cao $Y, X u$ $X$, Lei $H$. Synthesis and biological evaluation of new ligustrazine derivatives as anti-tumor agents. Molecules 2012; 17: 4972-4985.

16. Wang L, Yi X, Wang Z, Liu B, Chu F, Li G, Li Q, Lei H. Preparation and evaluation of potent cardiovascular drug-loaded PLGA microspheres based on early-stage preparation discovery concept. J Chem Pharm Res 2014; 6: 1135-1141.

17. Cheng $X C$, Liu $X Y, X u W F$, Guo $X L$, Zhang $N$, Song $Y N$. Ligustrazine derivatives. Part 3: Design, synthesis and evaluation of novel acylpiperazinyl derivatives as potential cerebrocardiac vascular agents. Bioorg Med Chem 2009; 17: 3018-3024.

18. Deng L, Guo $X$, Zhai L, Song $Y$, Chen $H$, Zhan $P, W u J$, Liu $X$. Ligustrazine derivatives. Part 4: Design, synthesis, and biological evaluation of novel ligustrazine-based stilbene derivatives as potential cardiovascular agents. Chem Bio Drug Des 2012; 79: 731-739.

19. Chen H, Li G, Zhan P, Li H, Wang S, Liu X. Design, synthesis and biological evaluation of novel trimethylpyrazine-2-carbonyloxy-cinnamic acids as potent cardiovascular agents. Med Chem Comm 2014; 5: 711-718.

20. Nör JE, Christensen J, Mooney DJ, Polverini PJ. Vascular endothelial growth factor (VEGF)-mediated angiogenesis is associated with enhanced endothelial cell survival and induction of Bcl-2 expression. Am J Pathol 1999; 154: 375-384.

21. Waltham M, Burnand KG, Collins M, Smith A. Vascular endothelial growth factor and basic fibroblast growth factor are found in resolving venous thrombi. $J$ Vasc Surg 2000; 32: 988-996.

22. Sun $Y$, Jin K, Xie L, Childs J, Mao XO, Logvinova A, Greenberg DA. VEGF-induced neuroprotection, neurogenesis, and angiogenesis after focal cerebral ischemia. J Clin Invest 2003; 111: 1843-1851.

23. Yang J, Yao Y, Chen T, Zhang T. VEGF ameliorates cognitive impairment in in vivo and in vitro ischemia via improving neuronal viability and function. VEGF ameliorates cognitive impairment in in vivo and in vitro ischemia via improving neuronal viability and function. Neuromolecular Med 2014; 16: 376-388.

24. Zhang A, Liang L, Niu H, Xu P, Hao Y. Protective effects of VEGF treatment on focal cerebral ischemia in rats. MOL MED REP 2012; 6: 1315-1318.

25. Ziu M, Fletcher L, Rana S, Jimenez DF, Digicaylioglu M. Temporal differences in microRNA expression patterns in astrocytes and neurons after ischemic injury. PloS one 2011; 6: e14724.

26. Wagenaar DA, Madhavan R, Pine J, Potter SM. Controlling bursting in cortical cultures with closed-loop multi-electrode stimulation. J Neurosci 2005; 25: 680688.

27. Chan JK. The Wonderful Colors of the HematoyxlinEosin Stain in Diagnostic Surgical Pathology. Int J Surg Pathol 2014; 1066896913517939.

28. Wang $P$, Zhang $Y, X u K$, Li Q, Zhang H, Guo J, Pang D, Cheng $Y$, Lei H. A new ligustrazine derivative-pharmacokinetic evaluation and antitumor activity by suppression of NF-kappaB/p65 and COX-2 expression in S180 mice. Pharmazie 2013; 68: 782-789.

29. An ZY, Yan YY, Peng D, Ou TM, Tan JH, Huang SL, An $L K$, Gu LQ, Huang ZS. Synthesis and evaluation of graveoline and graveolinine derivatives with potent antiangiogenesis activities. Eur J Med Chem 2010; 45: 3895-3903.

30. Li HQ, Wu XZ, Bai D, Yang YN, Lei HM. Screening active fraction of compound Sanhuang capsules for inhibition of angiogenesis in tumor. Chin. J. Exp Tradit Med. Formulae 2011; 17: 172-175.

31. Mao Y, Yang GY, Zhou LF, Stern JD, Betz AL. Focal cerebral ischemia in the mouse: description of a model and effects of permanent and temporary occlusion. Brain Res Mol Brain Res 1999; 63: 366-370.

32. Goldmacher GV, Nasser $R$, Lee DY, Yigit $S$, Rosenwasser $R$, lacovitti $L$. Tracking transplanted bone marrow stem cells and their effects in the rat MCAO stroke model. PloS one 2013; 8: e60049.

33. Bederson JB, Pitts LH, Tsuji M, Nishimura MC, Davis RL, Bartkowski H. Rat middle cerebral artery occlusion: evaluation of the model and development of a neurologic examination. Stroke 1986; 17: 472-476.

34. Talwar T, Srivastava MVP. Role of vascular endothelial growth factor and other growth factors in post-stroke recovery. Ann Indian Acad Neurol 2014; 17: 1-6.

35. Yan YP, Lang BT, Vemuganti R, Dempsey RJ. Galectin-3 mediates post-ischmic tissue remodeling. Brain Res 2009; 1288: 116-124. 